\title{
The Christmas Market Attack in Berlin and Attitudes Toward Refugees: A Natural Experiment with Data from the European Social Survey
}

\author{
Christof Nägel ${ }^{1}$ (D) $\cdot$ Mark Lutter $^{2}$
}

Received: 22 October 2019 / Accepted: 22 April 2020 / Published online: 12 May 2020

(c) The Author(s) 2020

\begin{abstract}
Using a quasi-experimental research design, this study examines changes in attitudes toward refugees after the terrorist attack on the Berlin Christmas market of December 19, 2016. In our analysis, we make use of random variation in the field period of the European Social Survey (ESS) to fashion a natural experimental design. The survey's field period took place in Germany from August 23, 2016, to March 26, 2017. Hence, the Christmas market attack took place approximately halfway through the ESS's field phase, thus making it possible to study the causal effect on changing attitudes toward minorities before and after the attack. We argue that the terrorist attack creates a spillover effect and negatively shapes public opinion of uninvolved ethnic minorities. Our data analysis suggests that immediately after the event, only people with a right-wing political attitude appear to be affected by the proposed spillover effect. However, we find that the worsening of attitudes toward refugees can also be observed in the general population as time progresses. We do not find variation according to educational levels.
\end{abstract}

Keywords Natural experiment $\cdot$ Attitudes toward refugees $\cdot$ Xenophobia $\cdot$ European Social Survey 2016 - Berlin Christmas market · Right-wing attitudes · Terrorist attack

Christof Nägel

christof.naegel@dhpol.de

Mark Lutter

lutter@uni-wuppertal.de

1 German Police University, Münster, Germany

2 University of Wuppertal, Wuppertal, Germany 


\section{Introduction}

While experimental designs are well established in empirical prejudice research, quasi-experimental designs such as natural experiments are steadily advancing toward the center of a sociological and socio-psychological analysis of xenophobic prejudices (Bertrand and Duflo 2016: 2). A comparison of current research on discrimination with older studies reveals that natural experiments have emerged as a promising research avenue (Boomgaarden and de Vreese 2007; Czymara and Schmidt-Catran 2017; Echebarria-Echabe and Fernández-Guede 2006; Legewie 2013; Muñoz et al. 2019, Nussio et al. 2019, Bove et al. 2020). These studies typically examine the influence of major events such as terrorist attacks on changes in attitudes toward members of minority groups. In these studies, a distinct event that occurred within the data collection period of a survey program is used as a quasi-experimental stimulus, thus forming a "natural" experiment. Muñoz et al. call this specific research avenue the "Unexpected Event during Survey Design" (UESD) (2019).

Many of these UESD studies, but not all (one exception is Ares and Hernández 2017), use terrorist attacks as a treatment variable and find evidence of a causal effect by which these events lead to increased negative stereotyping of minority groups. However, the causal evidence these studies provide is mixed. While some studies demonstrate quite robust effects of terrorist attacks on changes in attitudes toward minority groups (Czymara and Schmidt-Catran 2017; Hopkins 2010; Legewie 2013; Mancosu et al. 2018; Schüller 2016), a number of other studies indicate little or no effect (see, e.g., Finseraas and Listhaug 2013; Jungkunz et al. 2018; Smiley et al. 2017; Castanho Silva 2018).

Such a situation points to the need for further research in this area in order to foster a better understanding of the role that terrorist attacks play in cultivating negative attitudes toward minority groups. In this study, we use a recent drastic terrorist attack, the assault on the Berlin Christmas market of December 19, 2016, to study the causal effect on changing attitudes toward minorities. The broad media reception of the attack in connection with the ongoing discussions of problems of migration policy and the "refugee crisis" provides an ideal setting in which to conduct such a natural experiment. In doing so, we make use of random variation in the field period of the eighth edition of the European Social Survey (ESS) (ESS Round 8: European Social Survey Round 8 Data 2016). The survey's field period took place in Germany from August 23, 2016, to March 26, 2017. Hence, the Christmas market attack occurred at approximately the halfway point of the ESS's field phase.

In this study, we argue that the terrorist attack creates a spillover effect and negatively shapes public opinion regarding ethnic minorities. In particular, we expect that the attack leads to worsening attitudes toward refugees. Moreover, we expect that the worsening of attitudes toward refugees interacts with educational levels, that is, the effect is stronger among respondents with lower ability to differentiate between single events and uninvolved minority groups as a whole. Based on prior research findings, we also expect stronger spillover effects among people with right-wing political attitudes. 


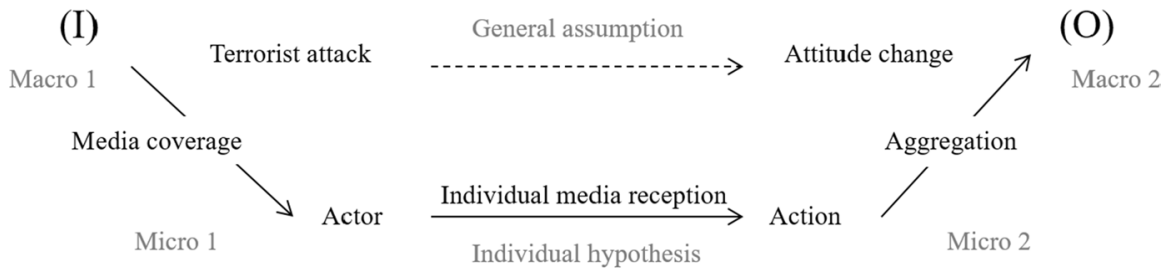

(M)

Fig. 1 Schematic representation of the relationship between terrorist attack and attitude change using the macro-micro-macro-model based on Coleman (1990) and Hedström and Swedberg (1998)

Larsen et al. (2019) find no effects in their more general analysis of the impact of the terrorist attack in Berlin on Euroscepticism in the form of anti-immigration, antirefugee, and anti-European Union sentiments in several European countries (Larsen et al. 2019). In contrast to Larsen et al. (2019), we suggest that the identification of the effect depends on methodological decisions such as the adjustment of the time bandwidth before and after the attack. In our analysis, we test how the effect changes with different bandwidths. The exploitation of different bandwidths in natural experiments with survey data is an important robustness check that previous studies, including Larsen et al. (2019), neglect (Muñoz et al. 2019). Furthermore, we show that only certain subpopulations are affected by the effect directly after the attack.

Our analysis reveals that the main effect turns out to be rather limited within a relatively short time window. However, in individuals who classify themselves politically right, deterioration in attitudes toward refugees can also be observed shortly after the terrorist attack. If we increase the bandwidth of our analysis, the effect becomes apparent in the entire sample, while the moderating effect of right-wing political attitudes disappears. Contrary to our expectations, we find no moderation effect with regard to education. The worsening of attitudes after the event does not vary according to educational level.

\section{Theory and Hypotheses: Mechanisms Explaining the Negative Relation Between Terrorist Attacks and Changes in the Perception of Minority Groups}

A relatively simple social mechanism that identifies a connection between terrorist attacks and changes in the perception of (foreign) groups associated with them can be theorized as a "spillover effect." A distinctive event such a violent terrorist attack evokes a collective change in attitude: Specifically, the spillover from media coverage of the event to media reception by the individual actor results in a change in his or her attitude. The spillover effect is displayed in Fig. 1: An input (I) determines an outcome (O), whereby the relationship between (I) and (O) is influenced or enabled by the mechanism (M) (Hedström and Swedberg 1998: 7).

The initial situation (macro 1 ) begins with the respective event. Though only a relatively small number of people were victims of the attack, from the perspective 
of the assassin and the terror organization associated with it, the attack can be seen as a strike against Western culture as a whole, namely a "Jihad against the Enemies of Allah" (Böckler et al. 2017), which is why the attack itself is to be located at the macro-level. The media coverage of the event, which we understand as a bridge hypothesis between the event and the individual actors, affects the actors' perception of the events at the micro-level (micro 1), which in turn causes a change in an individual's attitude (micro 2). This change in attitude is finally aggregated by means of the mechanism of adaptation or imitation and creates a macro-level collective change in public opinion (macro 2). Such a perspective underlines the idea that media act as "accomplices" of terrorism. Terrorists therefore need the media reaction in order to receive the necessary attention from society as a whole.

The social mechanism $(\mathrm{M})$ described here can be understood as a "spillover effect" or "transfer effect" (Schüller 2016: 604). The term describes the extent to which an event/state affects other events/states. Since both Schüller and Legewie investigate the impact of events that have taken place abroad, they require a bridge hypothesis that can explain the change in attitudes in a location far removed from the event. As Legewie argues in this context (Legewie 2013: 1204), other socio-psychological studies (for example, Spilerman and Stecklov 2009) have already pointed out that terrorist attacks abroad can also fuel the fears of the local population. These fears are most commonly associated with cases in which murders have been committed in the name of Islam, mainly against Muslims. However, since stereotypes are often generalized (Bodenhausen 1993), it seems quite plausible, as Legewie contends, that fears which fuel resentment extend to non-European migrants.

Accordingly, a terrorist attack carried out abroad in the name of Islam could have a negative impact on the perception of migrants who may not even be Muslim themselves. Czymara and Schmidt-Catran (2017: 736) criticize this use of a construct of items that have only an indirect relationship to the terrorists and their religious or idealistic motives, stating: "We argue that prior research has underestimated the effect of such events because it mixed up attitudes towards various immigrant subgroups, even though most of them were not associated with the respective event", it therefore seems appropriate in this paper not to generate the dependent variable from items that refer to the universal term migrants, but rather to use variables that allow an association with the event through a direct reference to refugees. ${ }^{1}$ Since in contrast to Jungkunz et al. (2018) and Schüller (2016), the two contributions by Finseraas et al. (2011) and Finseraas and Listhaug (2013), as well as the first study in Legewie (2013), our empirical case is not a terrorist event in a far-off location, but an attack in the German capital at Christmastime, we expect a spillover effect that leads to a worsening in attitudes toward refugees in the general German population. The appropriateness of this approach is underlined by the fact that shortly after the attack there was a discussion about whether the perpetrator came to Germany as a refugee. We will go into this in more detail later. Hence, based on the theoretical discussion above, we propose our first hypothesis as follows:

\footnotetext{
1 We test in additional regressions on attitudes toward migrants, whether our sole focus on attitudes toward refugees as an outcome is appropriate.
} 
H1 We expect a spillover effect from the terrorist event. The terrorist attack causes worsening attitudes toward refugees among German citizens.

Allport (1979) refers to the connection between a low level of education and negative attitudes toward minority groups and their cultural, religious, or social values. Reasons for this may include a lack of social competencies taught in schools, or the interest in "cosmopolitan issues" that is forced onto higher educational institutions, such as a better understanding of the potentially positive effects of European integration (Rusu and Gheorghita 2014: 264). A simple socio-psychological argument already discussed by Allport (1979) also considers the fact that people with lower levels of education are denied the ability to differentiate between the Muslim aggressor and a peaceful practice of religion. We therefore expect that the treatment effect is stronger for people with lower levels of education.

H2 The worsening of attitudes toward refugees will be more prevalent among people with lower educational levels.

A strengthening of the spillover effect in people with prior right-wing political attitudes intuitively seems plausible and can be explained by social theory in a straightforward fashion. In making this explanation, we are guided to a large extent by the considerations put forward by Peffley et al. (2015) as well as the empirical findings provided by Jungkunz et al. (2018). Peffley et al. (2015: 820) argue that people with right-wing political attitudes are more hostile to outside groups because they are more sensitive to threats to national security. Mass immigration as such can endanger this need for stability and security (Caprara et al. 2006). For rightwing individuals, the terrorist attack can thus be understood as a direct consequence of this mass migration, suggesting a potential enhancement of the spillover effect. Since, as Miller and Bugelski (1948) points out, perceived frustrations can cause aggression targeted at uninvolved minorities, we expect a heightened negative attitude toward refugees, post-attack, among people who report right-wing political attitudes.

H3 The worsening of attitudes toward refugees will be stronger among people who express a political right-wing attitude.

\section{Empirical Setting: The Terrorist Attack on the Berlin Christmas Market}

At 8 p.m. on December 19, 2016, the Islamist terrorist Anis Amri drove a truck into a crowd at the Christmas market at the Kaiser Wilhelm Memorial Church in Berlin. In the course of the attack, 11 visitors were struck and killed by the truck, and another 55 were injured. The twelfth victim of the devastating attack was the Polish driver of the semi-trailer, whom Amri shot and killed in the course of stealing his truck. Though Amri managed to escape after the attack, he was eventually shot 
dead by a police officer on December 23, 2016, during a personnel check in Sesto San Giovanni, north of Milan, Italy. The "Amaq News Agency," which functions as the news channel of the terrorist militia IS, announced on December 20, 2016, that the assassin had acted as a soldier of the Islamic State ${ }^{2}$ The explosive nature of the event was underlined in the weeks following the attack by the uncertainty as to whether the perpetrator had come to Germany as a refugee or not. German Chancellor Angela Merkel stated: "I know that it would be particularly difficult for us all to bear if it were to be confirmed that a person had committed this deed who had asked for protection and asylum in Germany. This would be especially repugnant to the many, many Germans who are involved in refugee aid on a daily basis, and to the many people who actually need our protection and who are striving for integration into our country" (Bundesregierung 2016: translated by authors). The tragedy rekindled the already extended discussion about the so-called refugee crisis. The ongoing political and media discussion about the (so far) most devastating Islamist terrorist attack on German soil shows that the event triggered a similar disruptive change in the public's perception of the so-called refugee crisis, as described by Czymara and Schmidt-Catran (2017: 737ff.), and as witnessed in the mass sexual harassment of women by North African asylum seekers on New Year's Eve, 2015-2016. The attack on the Berlin Christmas market in December 2016 can therefore be viewed as a comparable "major event."

\section{Data and Methods}

The quasi-experimental design of the present work is a result of the fact that the terrorist attack described took place on December 19, 2016, during the survey period in Germany (August 23, 2016-March 26, 2017) of the eighth edition of the ESS. By including questions on attitudes toward refugees in the country-specific data set for Germany, the ESS Round 8 survey offers the opportunity for a natural experiment that examines the effects of major events on the perception of refugees in Germany. The ESS is a cross-national survey that every 2 years reviews attitudes, beliefs, and behavior patterns in European countries on the basis of probability samples gathered through face-to-face interviews (ESS Round 8: European Social Survey Round 8 Data 2016). Principally, there is no reason to believe that respondents interviewed before the attack differ systematically from respondents interviewed after the attacks. Generally, the procedure for assigning interview dates is as follows: Every interviewer receives a number of sampled units with whom they attempt to make appointments. At least four unsuccessful personal visits must be attempted before a sampled unit is abandoned. We find it highly unlikely that the likelihood of the survey date for an individual should not be random. A detailed fieldwork and data documentation can be found at www.europeansocialsurvey.org. However, we will

\footnotetext{
${ }^{2}$ For a more detailed list of events before, during, and after the terrorist attack, see Biermann et al. (2016).
} 
nonetheless empirically explore to what extend there is a difference in respondents interviewed before and after the attack.

\subsection{Experimental Design ${ }^{3}$}

The terrorist attack on the Berlin Christmas market provides a causally exogenous experimental stimulus that randomly separates the control and experimental groups. Previous studies differ quite considerably in the time periods used to divide the groups. While Mancosu et al. (2018) argue for a shortened classification of control and experimental groups of a maximum of 3 days after the event in order to capture immediate effects, most studies cover a period of approximately 1 month before and after the event. For the present study, the approach proposed by Mancosu et al. (2018) does not appear to be appropriate for various theoretical and methodological reasons. Starting from the previously formulated social mechanism, such a limited temporal division is inadequate, since it makes it less likely that individuals will be influenced by media coverage of events on the microsocial level. The attack enables a change in attitude through media response, which is likely to take more than 3 days. Furthermore, a limiting of the time span does not make sense from a purely practical/methodological point of view, since a minimum time window of about 3 days would not allow an appropriate statistical analysis due to a diminished survey response rate in December. While in Mancosu et al. (2018), despite the short period of time, a numerically strong experimental group $(n=613)$ can nevertheless be set up, in the case of this study, only one experimental group with the strength of $n=64$ persons would remain given a time window of 3 days. For this reason, like the majority of previous studies, we refer to a period of \pm 30 days. However, we run additional regressions with other time periods as robustness checks (see below).

The following experimental setup is used. A variable "treatment" is created that obtains the value 0 if a person was interviewed 30 days before the attack and 1 if the interview took place 30 days after the attack. Since it cannot be said with certainty whether the interviews on December 19, 2016, were held just before or just after the attack, the testimony of persons interviewed on the day of the attack is also deleted from the record. In one case, an interview began on December 17, 2016, and ended on December 20, 2016. We removed that case from the analysis.

In contrast to some of the previous studies, we do not exclude persons with a migrant background from the analysis. This has the simple reason that our dependent variable does not ask for attitudes toward migrants, but for attitudes toward refugees. Persons with a migrant background may also be affected by the spillover effect described above. Additionally, people with a migrant background could, in this case, have stronger attitudes toward refugees than non-migrants because they are aware of the possible generalizations after the attack toward uninvolved groups and hence are afraid of negative consequences for themselves due to the attack. This results in a control group of $n=591$ respondents and an experimental group of $n=297$ respondents. The total subsample of the ESS for Germany contains $n=2852$ respondents. With $n=888$ persons, our sample consists of $31.14 \%$ of the total sample.

\footnotetext{
${ }^{3}$ Replication code can be accessed via: https://osf.io/wm9pz/.
} 
Table 1 Descriptive statistics of dependent and independent variables for control and treatment group

\begin{tabular}{lccll}
\hline Item & $M$ & SD & Min/Max & $N$ \\
\hline Treatment group & & & & \\
Dependent variable & 2.923 & .647 & $0 / 5$ & 271 \\
Age & 45.09 & 17.228 & $15 / 83$ & 300 \\
Female & .480 & .500 & $0 / 1$ & 300 \\
West & .860 & .350 & $0 / 1$ & 300 \\
Income_cat_1 (Ref.=fifth decile) & .048 & .214 & $0 / 1$ & 300 \\
Income_cat_2 & .136 & .343 & $0 / 1$ & 300 \\
Income_cat_3 & .112 & .315 & $0 / 1$ & 300 \\
Income_cat_miss & .149 & .357 & $0 / 1$ & 300 \\
Education & .233 & .423 & $0 / 1$ & 273 \\
Left/right & 4.300 & 1.879 & $0 / 10$ & 287 \\
Control group & & & & \\
Dependent variable & 2.882 & .654 & $0 / 5$ & 532 \\
Age & 46.750 & 18.322 & $15 / 94$ & 590 \\
Female & .490 & .500 & $0 / 1$ & 590 \\
West & .810 & .395 & $0 / 1$ & 590 \\
Income_cat_1 (Ref.=fifth decile) & .071 & .257 & $0 / 1$ & 590 \\
Income_cat_2 & .097 & .296 & $0 / 1$ & 590 \\
Income_cat_3 & .118 & .323 & $0 / 1$ & 590 \\
Income_cat_miss & .133 & .340 & $0 / 1$ & 590 \\
Education & .277 & .448 & $0 / 1$ & 515 \\
Left/right & 4.600 & 1.850 & $0 / 10$ & 571 \\
\hline & & & &
\end{tabular}

ref. reference category

\subsection{Dependent and Independent Variables}

Table 1 provides descriptive statistics of all dependent and independent variables in both control and treatment group. The dependent variable of this study is an additive index of seven items dealing with attitudes toward refugees contained in the ESS 2016 dataset. Three items were surveyed in all countries, while four are contained only in the German subsample used for this study. Each item is measured on a five-point Likert-type scale ranging from "Agree Strongly," "Agree," "Neither Agree nor Disagree," "Disagree," to "Disagree Strongly." Table 2 shows the variables, the descriptive statistics, and the individual factor loadings of the index. After recoding the direction of the items marked with $(-)$, the factor analysis shows a single factor with an eigenvalue above 1 (exactly 2.680) and an explained variance of $38.279 \%$. Reliability analysis shows a Cronbach's alpha of .72. The descriptive analysis of the normally distributed additive index shows a mean of 2.896 and a median of 2.857 , with a standard deviation of .651 scale points. Lower values in the index indicate high acceptance of refugees, while larger values indicate disapproving attitudes toward refugees. 
Table 2 Descriptive statistics and factor analyses of the items of the dependent variable, $n=802$

\begin{tabular}{llll}
\hline Item & $M$ & SD & Factor loadings \\
$\begin{array}{l}\text { "The government should be generous in judging people's applica- } \\
\text { tions for refugee status" }\end{array}$ & 3.350 & 1.116 & .732 \\
$\begin{array}{l}\text { "Refugees whose applications are granted should be entitled to bring } \\
\text { in their close family members" }\end{array}$ & 2.650 & 1.072 & .707 \\
$\begin{array}{l}\text { "Most applicants for refugee status aren't in real fear of persecution } \\
\text { in their own countries." (-) }\end{array}$ & 3.015 & 1.002 & .659 \\
$\begin{array}{l}\text { "There is a bigger ratio of refugees in Germany than accorded." (-) } \\
\text { "Refugees should have an employment permit during their applica- } \\
\text { tion process" }\end{array}$ & 3.605 & 1.027 & .537 \\
"Refugees should stay in reception camp during their application & 2.764 & 1.108 & .474 \\
$\begin{array}{l}\text { process." (-) } \\
\text { "Refugees should get financial support during their application } \\
\text { process" }\end{array}$ & 2.570 & 1.027 & .607 \\
\hline
\end{tabular}

The independent variables of this study include the control variables, which are only of secondary interest, the dichotomous treatment variable, and the product terms of the predictors with the treatment variable. As described in detail above, the treatment variable measures the time window before and after the event; it is 0 for cases 30 days before, and 1 for cases 30 days after the attack.

We use the following control variables: age, which is the age in years of the respondents; female is a gender dummy that is 1 for females and 0 for males; west is a location dummy that is 1 for respondents from the western part of Germany and 0 for the eastern part. Income is the household net income, measured in deciles. We created a set of dummy variables containing three deciles each and added a residual category for the missing cases due to many missing values. This results in four dummy variables (one for the missing cases), while the fifth decile is used as the reference level. The ESS measures education on a 25-point scale, where the highest value represents the doctoral level. We created a dummy variable for college degree or above to facilitate interpretation. Left/right measures political self-rating on a tenpoint scale $(0=$ politically left, $10=$ politically right $)$. From these last two variables, we form product terms with the treatment variable in order to test the interaction effects suggested by hypotheses $\mathrm{H} 2$ and $\mathrm{H} 3$.

\subsection{Model Specification and Control of the Experimental Situation}

The calculated model resembles a regression discontinuity design and can be formally defined as follows (equation according to a model with full set of controls and interaction terms):

$$
Y_{i}=\beta_{0}+\beta_{1} T_{i}+\beta_{2} X_{2 i}+\cdots+\beta_{10} X_{10 i}+\beta_{11}\left(T X_{9 i}\right)+\beta_{12}\left(T X_{10 i}\right)+\varepsilon_{i}
$$

$T$ is the dummy variable of the treatment effect and $\beta_{1}$ the corresponding slope coefficient. The coefficients $\beta_{2}$ to $\beta_{10}$ are multiplied by the respective values of the 
covariates $X_{2}$ to $X_{10}$ listed above. $B_{11}$ and $\beta_{12}$ are the slope coefficients of the predictors from which product terms of the form $\beta_{k}\left(T X_{k}\right)$ are formed by means of the dichotomous treatment variable. These product terms are used as interaction effects in the model. The model itself is estimated by way of ordinary least squares (OLS).

Prior to the main analysis, we checked several assumptions of the OLS model, including the linearity between the independent variables, the occurrence of statistical outliers, the independence of the residuals, multicollinearity between the independent variables, homoskedasticity, and the normal distribution of the residuals. To address the problem of multicollinearity, which frequently occurs in the calculation of interaction effects, the treatment variable and the four predictors from which the product terms are formed were centered on the mean value before the calculation of the model. This approach is recommended by Cronbach (1987), among others, to avoid multicollinearity of interaction effects. Other approaches criticize this method in the sense that centering only adjusts the characteristic values for tolerance, variance inflation, and the condition index, while the problem of multicollinearity remains (Echambadi and Hess 2007; Frazier et al. 2004). Though we share this view, we refer to the established practice of mean-centering, since imperfect multicollinearity, especially in small samples, leads merely to a more difficult identification of significant results. Apart from this, all OLS assumptions are satisfied.

In order to determine to what extent the experimental setting can be described as truly experimental, the homogeneity of the control and experimental groups is checked by means of an imbalance analysis. An imbalance analysis, which is used by Legewie (2013: 1211) or Mancosu et al. (2018: 7) and recommended by Muñoz et al. (2019), is basically a logistic regression model that is used for testing the quality of the experimental design. The methodology is as follows. The treatment variable forms the dependent variable in a binary logistic regression, while all control variables and the variables from which the interaction terms are formed make up the exogenous part of the model. In this way, one is able to check whether one or more of the independent variables can significantly explain the probability of belonging to the experimental group. Such a case would point to an unequal distribution of the two groups with regard to this variable. The results can be seen in Table 3. The imbalance analysis suggests that the treatment group has slightly more people from West Germany, as well as more people with a left attitude.

In fact, this distribution is confirmed by a descriptive comparison. Thus, we cannot interpret the treatment effect as an unbiased estimator of the causal effect, since the assumption of equal distribution of the groups with respect to the chosen variables cannot be fulfilled. Since the left-right self-rating correlates with the dependent variable (Pearson's $R=.343 ; p \leq .001$ ) and since people from East Germany have significantly higher values in the dependent variable than people from West Germany (mean difference $=.305 p \leq .001$ ), it is reasonable to assume that the unequal distribution causes a downward distortion of the causal effect. To achieve unbiased estimates, we therefore rely on a model controlling for these imbalances. In addition, we use a matching procedure to balance the groups. 
Table 3 Binary logistic regression with treatment as dependent variable

\begin{tabular}{|c|c|}
\hline & M 0 \\
\hline Constant & $\begin{array}{l}-.188 \\
(.346)\end{array}$ \\
\hline Age & $\begin{array}{l}-.003 \\
(.004)\end{array}$ \\
\hline Gender & $\begin{array}{l}-.242 \\
(.156)\end{array}$ \\
\hline West & $\begin{array}{l}.446^{*} \\
(.217)\end{array}$ \\
\hline Education & $\begin{array}{l}-.284 \\
(.183)\end{array}$ \\
\hline Income_cat_1 (Ref. = fifth decile $)$ & $\begin{array}{l}-.198 \\
(.341)\end{array}$ \\
\hline Income_cat_2 & $\begin{array}{l}.447^{+} \\
(.248)\end{array}$ \\
\hline Income_cat_3 & $\begin{array}{l}-.042 \\
(.255)\end{array}$ \\
\hline Income_cat_miss & $\begin{array}{l}.018 \\
(.043)\end{array}$ \\
\hline Left/right & $\begin{array}{l}-.119 * * \\
(.043)\end{array}$ \\
\hline Observations & 896 \\
\hline Cox and Snell $R^{2}$ & .027 \\
\hline Nagelkerkes $R^{2}$ & .037 \\
\hline
\end{tabular}

Standard errors in parentheses. Two-tailed tests

$* * p \leq .01, * p \leq .05,{ }^{+} p \leq .1$

\section{Results}

Table 4 shows the results of the analysis for a period of 30 days before and 30 days after the attack. We first calculate a baseline model, then a model with control variables, and finally a model with the full set of control and interaction terms. Information on the control variables is displayed in Table 6 in Appendix. We fix missing values on the amount of missing cases in the complete model. Contrary to what we expect with H1, Models 1 and 2 do not show any significant treatment effect within this timeframe. This suggests that a main spillover effect cannot be confirmed for the first 30 days after the attack. In the last model of Table 4, in which we include controls and the proposed interaction effects, the treatment effect turns significant, however. Since the variables are mean-centered, the treatment effect can be read as a primary effect in this model. The model shows that the treatment effect points in the predicted direction and is significant for $p \leq .05$. This points to a "conditional" confirmation of H1: Individuals interviewed 30 days after the attack have a higher value in the dependent variable "rejection of refugees" than respondents interviewed 30 days before the attacks, conditional on controlling for the proposed interaction effects. This means that if we let the model control the changing effect of the 
Table 4 OLS estimation of the effect of the attack with respective interactions; dependent variable is the index of disapproval of refugees

\begin{tabular}{llll}
\hline & M 1 & M 2 & M 3 \\
\hline Constant & $2.861 * * *$ & $3.062^{* * *}$ & $3.062^{* * *}$ \\
& $(.031)$ & $(.085)$ & $(.085)$ \\
Treatment & .030 & $(.043$ & $.095^{*}$ \\
& $(.052)$ & $(.050)$ & $(.048)$ \\
Controls & No & Yes & Yes \\
Treatment $\times$ education & & & .083 \\
& & & $(.103)$ \\
Treatment $\times$ left/right & & & $.050 *$ \\
& & & $(.025)$ \\
Observations & 693 & 693 & 693 \\
$R^{2}$ & .000 & .103 & .215 \\
$R_{\text {adj. }}^{2}$ & -.001 & .092 & .201 \\
\hline
\end{tabular}

Standard errors in parentheses. Two-tailed tests. Both the main effect and the interaction effect are centered on the mean. Results of the control variables displayed in Table 6 in the appendix

$* * * p \leq .001, * p \leq .05$

treatment depending on values of the interacted variables, the effect increases and becomes a significant effect.

Regarding the second hypothesis, $\mathrm{H} 2$, by which we expect stronger attitudinal changes among people with lower educational levels, the results seem not to confirm $\mathrm{H} 2$, since the coefficient of the interaction is not significant. As for H3, which anticipates stronger attitudinal changes among those who consider themselves politically more right-wing, the results do seem to partly confirm the assumption. The interaction between the left/right self-identification and the treatment effect shows a significant effect at the 5\% level. This result suggests that persons who were interviewed after the attack $(T=1)$ and reported a more right-wing position exhibit a more pronounced disapproval of refugees than persons in the control group with comparable political positioning. At the same time, the main treatment effect becomes significant as well. Nevertheless, the magnitude of the main and interaction effect is relatively weak. The treatment effect in Model 3, for instance, suggests that respondents show on average about .095 points stronger disapproval of refugees on the five-point scale.

Next, Table 5 estimates the treatment effect and the interaction terms using six alternative time windows, each for a baseline model without controls and a model with full controls (see again Table 6 in the Appendix for full information on the results of the control variables). For a very large model involving \pm 60 days before and after attack or the whole sample, the treatment effect is distinctly more pronounced and significant at $p \leq .01$ and $p \leq .001$ with and without controls, respectively. The interaction with left-right self-classification, however, disappears. The main effect becomes smaller with a smaller bandwidth; conversely, the left/right interaction effect becomes larger with a smaller bandwidth. Figure 2 plots the development of the coefficients over these different time windows. 
These results suggest that it may not be the attack per se, but the broad public discussion or the heated political debate in the aftermath of the attack that intensified the effect. Immediately after the attack, only persons with a prior political rightwing attitude appear to be affected by the spillover effect. However, as suggested by the increase of the treatment effect over time, these negative attitudes spread to the general population.

We also conducted falsification tests to check for the reliability of our estimates and to improve the overall validity of our research design. In this, we orient ourselves on the sensitivity analyses used by Finseraas and Listhaug (2013), since our design is similar in many respects. We run so-called placebo-regressions, where we "pretend" that the attack happened exactly 1 or 2 month before or 1 or 2 month after the attack. We find no significant main or interaction effect in any of these placeboregressions (tables not included). Additionally, we considered an alternative strategy to estimate the main effect. We estimate the causal effect through coarsened exact matching (CEM) in a number of weighted least squares regressions for all time windows using the R package CEM (Iacus et al. 2009). CEM "coarsens" values from a set of variables (the exogenous covariates used in this study) by creating a set of strata, each with the same coarsened values of these variables. Units in strata that do not contain at least one treatment and one control unit are pruned from the analysis (Iacus et al. 2012). Results largely confirm those without CEM. The main effect is significant and more pronounced for large models (bandwidth $\geq \pm 40$ days). It ranges from a "Sample Average Treatment Effect on the Treated" (SATT) of .122 for $p \leq .001$ (complete bandwidth) to SATT $=.094$ for $p \leq .05$ ( \pm 40 days). And the interaction with left-right self-classification is significant and more pronounced for smaller models (bandwidth $\leq \pm 50$ days), from $B=.048$ for $p \leq .05$ ( \pm 50 days) to $B=.141$ for $p \leq .05$ ( \pm 20 days).

Finally, we also employ a full regression discontinuity design (RDD) (Angrist and Pischke 2008) using the R package RDD provided by Dimmery (2016). Here, two OLS models are estimated; one before and one after the attack by applying the Imbens and Kalyanaraman (2012) method for obtaining optimal bandwidth. A comparison of the models shows no significant difference with respect to the intercepts of the models. The "Local Average Treatment Effect" (LATE) equals .074, with $p=.853$. These results underline our interpretation that a deterioration in attitudes toward refugees is not immediately apparent, but after an extended interval of time.

As elaborated above, we follow Czymara and Schmidt-Catran (2017) in generating our outcome variable from items focussed on attitudes toward refugees instead of analyzing the effects of the terrorist attack on attitudes toward migrants since there was a debate following the days after the attack about whether the perpetrator came to Germany as an refugee or not. This makes it likely that only attitudes toward refugees would deteriorate after the attack. Regressions on items that are not specifically asking about refugees might plausibly lead to an underestimation of the effect. We can, however, test this assumption by running parallel models on two indices generated from items concerning attitudes toward migrants. Running regressions on the specified bandwidth of \pm 30 days reveals that neither main nor interaction effects have a significant impact on these latent constructs (see Tables 7, 8 and 9 in the appendix for factor analyses and regression results). This validates our 


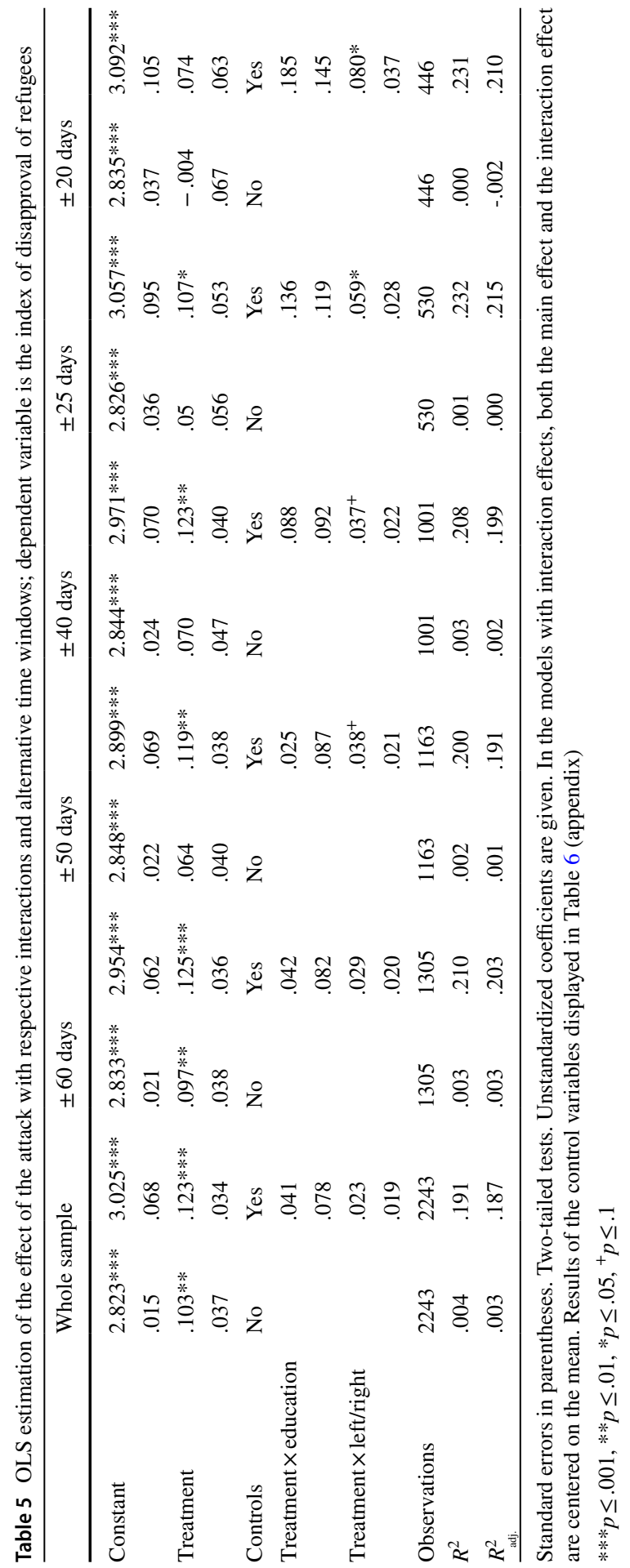


assumption that people differentiate between refugees and migrants after the attack. Furthermore, it implies that the composition of the dependent variable's items might be essential for identifying effects in comparable research designs.

\section{Conclusions}

The theoretical and empirical results of this study can be summarized as follows. The theoretical argument links the initial reaction to the attack on Breitscheidplatz in Berlin (that is, a decline in the acceptance of refugees) to the broad media reception, which we largely base on prior research on the relevance of media reporting (Castanho Silva 2018; Czymara and Schmidt-Catran 2017; Legewie 2016). In particular, we argue that a spillover effect negatively shapes public opinion regarding uninvolved refugees. In contrast to prior research, our study is able to highlight the relevance of a direct reference to the foreign group associated with the event, which is why the dependent variable in this paper consists of items that measure attitudes toward refugees rather than using the generalized term "migrants." Our description of the controversy as to whether the assassin was a refugee or not further emphasizes the importance of this distinction.

Among the contributions to date, some have been able to identify a deterioration in attitudes toward foreign groups following extreme terrorist attacks and comparable events (Legewie 2013; Czymara and Schmidt-Catran 2017; Schüller 2016; Hopkins 2010; Mancosu et al. 2018). Not only were significant effects of national events found, but also transfer effects of events that took place far away, such as in Bali or Mumbai.

According to our analysis, the effect of the terrorist attack on the Berlin Christmas market on December 19, 2016, on attitudes toward refugees depends on the selected timeframe. Based on a restricted timeframe of \pm 30 days, the treatment is only significant when we include controls and the proposed interaction effects. When we further enlarge the time window before and after the attack from \pm 30 to \pm 60 days, the effect becomes stronger (and significant); when we reduce the time window to \pm 20 days, the effect turns insignificant. Therefore, the results of the present work stand between those studies mentioned above and those which yielded only statistically weak or insignificant effects for comparable events (Castanho Silva 2018; Finseraas et al. 2011; Finseraas and Listhaug 2013; Jungkunz et al. 2018; Smiley et al. 2017).

The second hypothesis, that of a deleterious effect on attitudes toward refugees on the part of persons with lower levels of education, which Schüller (2016) suggests, is not supported by the analysis. The worsening of attitudes after the event does not correlate with educational levels, no matter what time window we employ.

Our analysis offers some evidence for the mediating effect of right-wing political self-classification. We find that the treatment effect is stronger among persons who self-classify themselves as politically right wing. The result confirms not only the study results of Jungkunz et al. (2018), but also assumptions of Peffley et al. (2015) and Caprara et al. (2006). The authors argue that conservative values or a political right-wing self-classification corresponds to the human need to control one's 


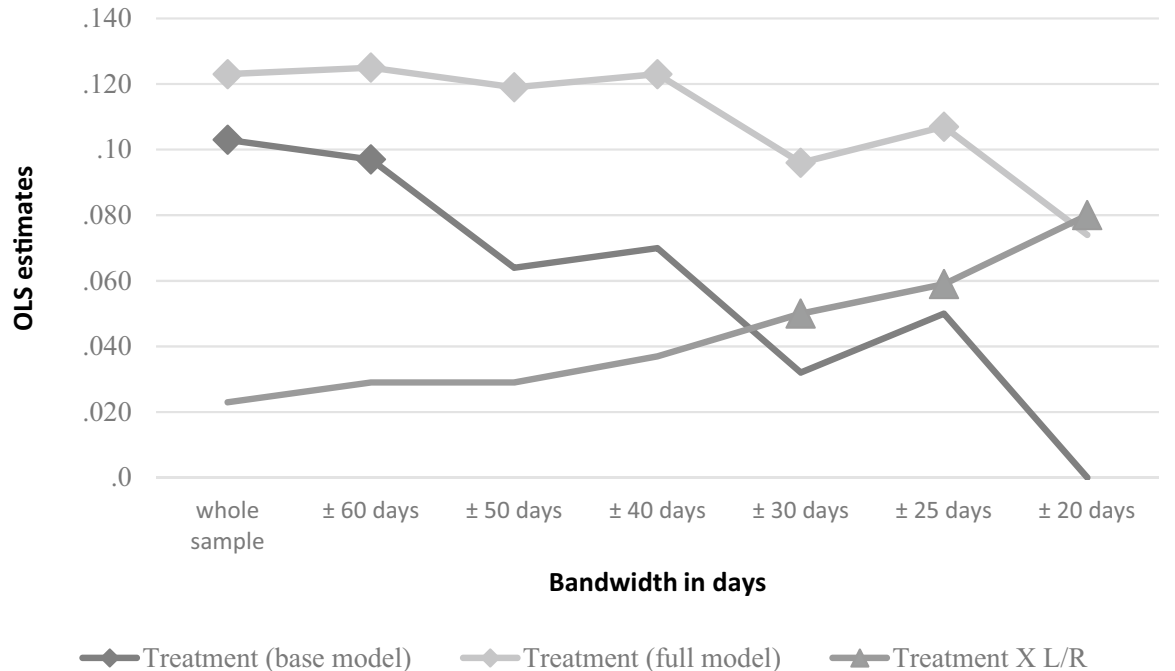

Fig. 2 Development of coefficient sizes for different time periods. Coefficients of the main effects and of the interaction effect with the left-right self-rating are given. Coefficients that are significant for at least $p \leq .05$ are marked

environment and maintain a subjective sense of security. According to this interpretation, these attitudes would correspond to the desire for social persistence, whichas a result of this work-is especially susceptible to disruptive events such as terrorist attacks and generates resentment toward the supposed dangers of this conservative view of the world. Caprara et al. (2006) argue that mass immigration poses a threat to this stability, and our findings confirm those of Jungkunz et al. (2018) that terrorist attacks also endanger this stability and that right-wing individuals are more negative toward refugees after the attack. In contrast to the temporal development of the main effect, this interaction effect can only be recognized immediately after the attack. We would therefore like to further emphasize the point already mentioned, namely that the terrorist attack per se can only be understood as a treatment for people with a right-wing attitude; the rest of the population, on the other hand, seems to be affected by the spillover effect only after a longer period of time. Here it makes sense to assume that the entire heated public discussion about the so-called refugee crisis, rekindled by the attack, should be understood as a treatment. This argumentation would justify a longer period of time as a treatment period. This, however, increases the danger of non-observable biases. In their quantitative media data analysis, Schmidt-Catran and Czymara (2020) come to the conclusion that the attack on the Berlin Christmas market only attracted the attention of the media for a very short time. Hence, we cannot make a direct connection between the media discussion and a deterioration of attitudes toward refugees after a longer period of time. It is possible, however, that refugees and terrorist attacks were increasingly 
discussed through other means of communication. One conceivable way would be interpersonal communication (also see Kalogeropoulos and Hopmann 2019), which unfortunately is difficult to examine retrospectively. In order to explore this in more detail, qualitative ethnographic approaches would be appropriate to study individual communication about refugees before and after terrorist attacks.

This study has limitations. As discussed above, one limitation is the non-comparability of the control and experimental groups with regard to the left-right self-assessment and the location of the interview. By pure chance, persons in the treatment group show more politically left self-classifications and interviews took place more often in the old federal states of Germany as compared to the control group. For this reason, we use these variables as control variables in our regression models. Related to this, the political self-classification variable can be considered as potentially endogenous because attitudes toward refugees likely affect one's own political self-classification as well as vice versa. In that sense, the left-right self-classification scale is probably a "bad control" from a causal inference perspective (Angrist and Pischke 2008). For this reason, we discuss and consider all model results without any controls as well. Even if it is a bad control variable, it makes sense to integrate the variable into a model for two reasons: Since the two groups differ with regard to the left-right self-classification, keeping this variable constant can reveal a possible effect, which otherwise would be concealed by the unequal distribution of the two groups. In addition, it helps us to shed some light on the mechanism that seems to be responsible for the deterioration of attitudes toward refugees immediately after the attack.

Another potential limitation is that the dataset does not offer the possibility of checking the well-known "contact hypothesis," or "intergroup contact theory," that is an important micro explanation of why people may hold biases against members of minority groups. The contact hypothesis goes back to Gordon W. Allport's The Nature of Prejudice (Allport 1979), a work whose findings have been empirically elaborated on by, for example, Pettigrew (1998). The idea is that stereotypes and negative attitudes toward foreign groups diminish with exposure to members of those groups. Unfortunately, the contact hypothesis cannot be tested in this study, as the ESS 2016 does not contain an item that asks for the frequency of contact with foreigners or refugees. However, the quasi-experimental design of the study is meant to rule out any possible bias from this omission due to randomization of the control and treatment groups.

Other reasonable hypotheses that combine the treatment effect with, for instance, measures of relative deprivation or a general fear of terrorism could also not be tested here with the available data. However, this creates an important opportunity for continuing research. Future studies could further explore the interrelationships to relative deprivation. In addition, new studies should look more closely at the temporal development of treatment effects.

In summary, the contribution of our study amounts to two essential findings. On the one hand, the main effect proves to be robust only for a very long time interval. We cannot rule out the possibility that the attack may have led to a 
deterioration in attitudes toward refugees, but it is likely that a general shift in the public's attitudes has taken place that is not solely due to the attack. Larsen et al. (2019) do not identify this effect because the bandwidth they used for their analysis is probably too narrow. On the other hand, we find some evidence that an immediate deterioration in attitudes toward refugees is only evident in people with right-wing attitudes. This link was already identified by Jungkunz et al. (2018), but the authors use a sample on a population of students. Our results show that those of Jungkunz et al. (2018) can also be transferred to a more representative sample.

Natural experiments comprise only one of many ways to uncover complex social mechanisms related to xenophobic attitudes. In order to investigate the connection between terrorist events and changes in attitudes, socio-psychological approaches like that of Rubaltelli and Pittarello (2018), which directly examine the emotional involvement after terrorist attacks and use it as a treatment variable, also seem to offer a very fruitful approach. Further, van Dooremalen (2017) discusses the pros and cons of using qualitative methods to research spillover effects following major events like terrorist attacks, which could provide another fruitful avenue for future research.

Acknowledgments Open Access funding provided by Projekt DEAL.

Open Access This article is licensed under a Creative Commons Attribution 4.0 International License, which permits use, sharing, adaptation, distribution and reproduction in any medium or format, as long as you give appropriate credit to the original author(s) and the source, provide a link to the Creative Commons licence, and indicate if changes were made. The images or other third party material in this article are included in the article's Creative Commons licence, unless indicated otherwise in a credit line to the material. If material is not included in the article's Creative Commons licence and your intended use is not permitted by statutory regulation or exceeds the permitted use, you will need to obtain permission directly from the copyright holder. To view a copy of this licence, visit http://creativecommons.org/licen ses/by/4.0/.

\section{Appendix}

The first index (Allow_Migrants) has one eigenvalue above 1 (exactly 2.202) and explains $73.396 \%$ of the variance of the latent construct. Cronbach's alpha for that index is .827. The index ranges from 1 (Allow many to come and live here) to 4 (Allow none). The three items of the second index (Anti_Migrants) are measured on an eleven-point Likert scale ranging from 0 (Bad for the economy/Cultural life undermined/Worse place to live) to 10 (Good for the economy/Cultural life enriched/ Better place to live). Again, the index has one eigenvalue above 1 (exactly 2.279), an explained variance of $75.976 \%$ and an Cronbach's alpha of .844 


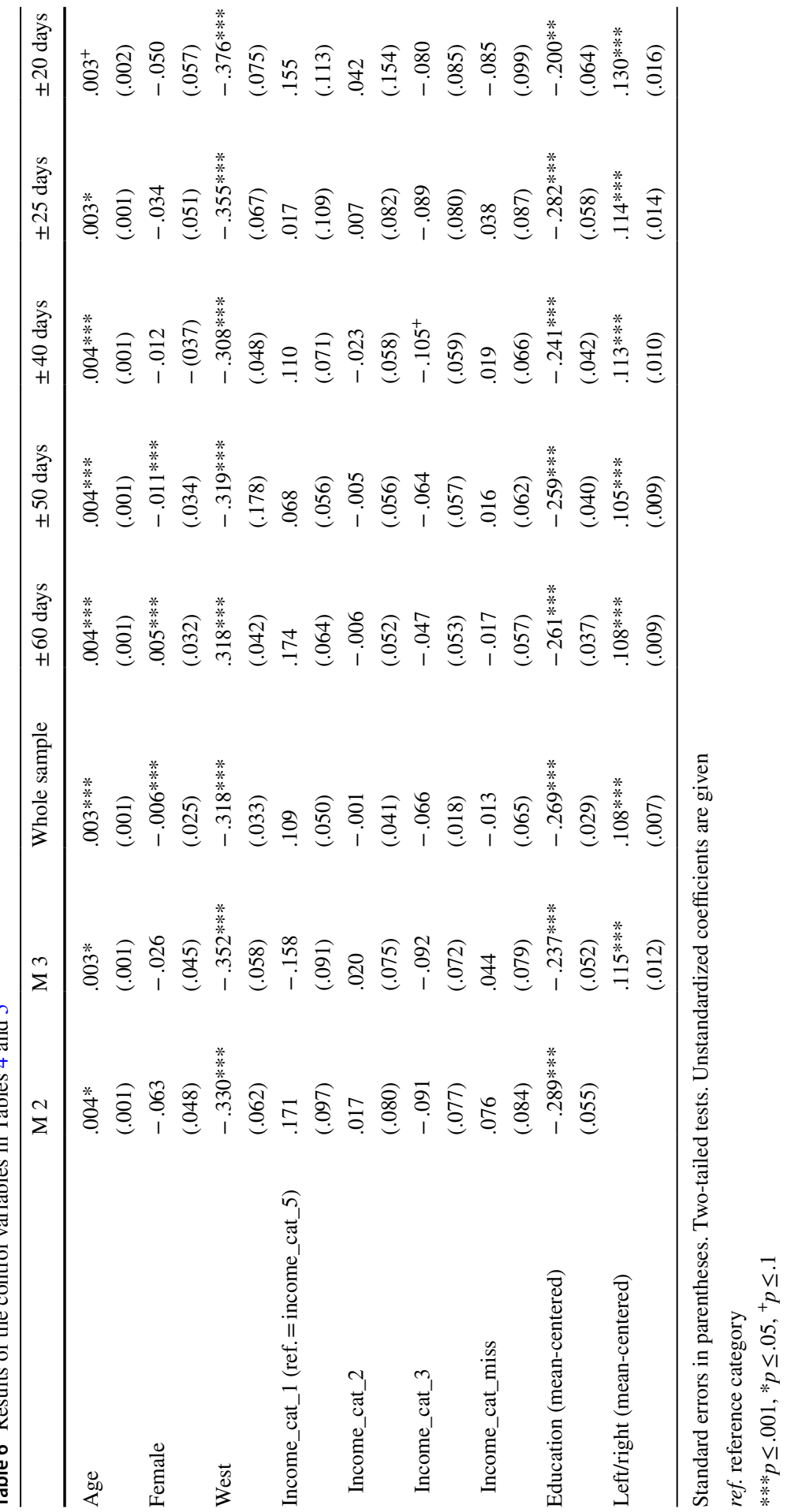


Table 7 Descriptive statistics and factor analyses of the alternative dependent variables

\begin{tabular}{|c|c|c|c|}
\hline Item & M & SD & Factor loadings \\
\hline $\begin{array}{l}\text { "(...) to what extent do you think Germany should allow people } \\
\text { of the same race or ethnic group as most Germans to come } \\
\text { and live here" }\end{array}$ & 1.71 & .702 & .828 \\
\hline $\begin{array}{l}\text { "How about people of a different race or ethnic group from } \\
\text { most Germany people" }\end{array}$ & 2.08 & .787 & .916 \\
\hline "How about people from the poorer countries outside Europe?" & 2.15 & .828 & .844 \\
\hline $\begin{array}{l}\text { "Would you say it is generally bad or good for Germany's } \\
\text { economy that people come to live here from other countries?" }\end{array}$ & 5.89 & 2.298 & .829 \\
\hline $\begin{array}{l}\text { "(...) would you say that Germany's cultural life is generally } \\
\text { undermined or enriched by people coming to live here from } \\
\text { other countries?" }\end{array}$ & 6.00 & 2.517 & .855 \\
\hline $\begin{array}{l}\text { "Is Germany made a worse or a better place to live by people } \\
\text { coming to live here from other countries?" }\end{array}$ & 5.30 & 2.184 & .909 \\
\hline
\end{tabular}

Table 8 OLS estimation of the effect of the attack with respective interactions; dependent variable is the index Allow_Migrants

\begin{tabular}{llll}
\hline & M 17 & M 18 & M 19 \\
\hline Constant & $1.972 * * *$ & $2.142 * * *$ & $2.142 * * *$ \\
& $(.030)$ & $(.091)$ & $(.089)$ \\
Treatment & -.011 & .003 & .032 \\
& $(.052)$ & $(.050)$ & $(.049)$ \\
Controls & No & Yes & Yes \\
Treatment $\times$ education & & & .095 \\
& & & $(.112)$ \\
Treatment $\times$ left/right & & & .008 \\
& & & $(.026)$ \\
Observations & 745 & 745 & 745 \\
$R^{2}$ & .000 & .091 & .150 \\
$R^{2}$ & -.001 & .080 & .136 \\
\hline adj. & & & \\
\hline
\end{tabular}

Standard errors in parentheses. Two-tailed tests. Both the main effect and the interaction effect are centered on the mean. Bandwidth $= \pm 30$ days

$* * * p \leq .001$ 
Table 9 OLS estimation of the effect of the attack with respective interactions; dependent variable is the index Anti_Migrants

\begin{tabular}{llll}
\hline & M 20 & M 21 & M 22 \\
\hline Constant & $5.742 * * *$ & $4.993 * * *$ & $4.993 * * *$ \\
& $(.092)$ & $(.267)$ & $(.267)$ \\
Treatment & .030 & .015 & -.125 \\
& $(.157)$ & $(.153)$ & $(.147)$ \\
Controls & No & Yes & Yes \\
Treatment $\times$ education & & & .295 \\
& & $(.336)$ & $(.112)$ \\
Treatment $\times$ left/right & & & -.081 \\
& & $(.079)$ & $(.026)$ \\
Observations & 743 & 743 & 743 \\
$R^{2}$ & .000 & .080 & .162 \\
$R_{\text {adj. }}^{2}$ & -.001 & .069 & .148 \\
\hline
\end{tabular}

Standard errors in parentheses. Two-tailed tests. Both the main effect and the interaction effect are centered on the mean. Bandwidth $= \pm 30$ days

$* * * p \leq .001$

\section{References}

Allport GW (1979) The nature of prejudice. Addison-Wesley Pub. Co, Reading

Angrist JD, Pischke J-S (2008) Mostly harmless econometrics: an empiricist's companion. Princeton University Press, Princeton

Ares M, Hernández E (2017) The corrosive effect of corruption on trust in politicians: evidence from a natural experiment. Res Polit. https://doi.org/10.1177/2053168017714185

Bertrand M, Duflo E (2016) Field experiments on discrimination. NBER Working Paper No. 22014. http://www.nber.org/papers/w22014

Biermann K, Faigle P, Geisler A et al (2016) Was wir über den Anschlag in Berlin wissen. Zeit-Online. https:/www.zeit.de/gesellschaft/zeitgeschehen/2016-12/berlin-breitscheidplatz-gedaechtniskircheweihnachtsmarkt. 29 Dec 2016, Last Accessed 5 Feb 2019

Böckler N, Hoffmann J, Meloy JR (2017) "Jihad against the enemies of Allah": the Berlin Christmas market attack from a threat assessment perspective. Violence Gend 4:73-80. https://doi.org/10.1089/ vio. 2017.0040

Bodenhausen GV (1993) Emotions, arousal, and stereotypic judgments: a heuristic model of affect and stereotyping. In: Mackie DM, Hamilton DL (eds) Affect, cognition, and stereotyping: interactive processes in group perception. Academic Press, San Diego, pp 3-37

Boomgaarden HG, de Vreese CH (2007) Dramatic real-world events and public opinion dynamics: media coverage and its impact on public reactions to an assassination. Int J Public Opin Res 19:354-366. https://doi.org/10.1093/ijpor/edm012

Bove Vincenzo, Böhmelt Tobias, Nussio Enzo (2020) Terrorism abroad and migration policies at home. J Eur Public Policy. https://doi.org/10.1080/13501763.2020.1729227

Bundesregierung (2016) Pressestatement von Bundeskanzlerin Merkel zum mutmaßlichen Anschlag am Breitscheidplatz in Berlin. https://www.bundesregierung.de/Content/DE/Mitschrift/Pressekonferenz en/2016/12/2016-12-20-erklaerung-merkel-breitscheidplatz.html. Accessed 5 Feb 2019

Caprara GV, Schwartz S, Capanna C et al (2006) Personality and politics: values, traits, and political choice. Polit Psychol 27:1-28. https://doi.org/10.1111/j.1467-9221.2006.00447.x

Castanho Silva B (2018) The (non)impact of the 2015 Paris terrorist attacks on political attitudes. Person Soc Psychol Bull 44:838-850. https://doi.org/10.1177/0146167217752118

Coleman J (1990) Foundations of social theory. Harvard University Press, Cambridge 
Cronbach LJ (1987) Statistical tests for moderator variables: flaws in analyses recently proposed. Psychol Bull 102:414-417. https://doi.org/10.1037/0033-2909.102.3.414

Czymara CS, Schmidt-Catran AW (2017) Refugees unwelcome? Changes in the public acceptance of immigrants and refugees in Germany in the course of Europe's 'immigration crisis'. Eur Sociol Rev 33:735-751. https://doi.org/10.1093/esr/jcx071

Dimmery D (2016) rdd: regression discontinuity estimation ( $\mathrm{R}$ package version 0.57 ). Retrieved from https://CRAN.R-project.org/package=rdd

Echambadi R, Hess JD (2007) Mean-centering does not alleviate collinearity problems in moderated multiple regression models. Mark Sci 26:438-445. https://doi.org/10.1287/mksc.1060.0263

Echebarria-Echabe A, Fernández-Guede E (2006) Effects of terrorism on attitudes and ideological orientation. Eur J Soc Psychol 36:259-265. https://doi.org/10.1002/ejsp.294

ESS Round 8: European Social Survey Round 8 Data (2016) Data file edition 2.1. NSD—Norwegian Centre for Research Data, Norway-data archive and distributor of ESS data for ESS ERIC. https:// doi.org/10.21338/nsd-ess8-2016

Finseraas H, Listhaug O (2013) It can happen here: the impact of the Mumbai terror attacks on public opinion in Western Europe. Public Choice 156:213-228. https://doi.org/10.1007/s1112 7-011-9895-7

Finseraas H, Jakobsson N, Kotsadam A (2011) Did the murder of Theo van Gogh change Europeans' immigration policy preferences? Kyklos 64:396-409. https://doi.org/10.111 1/j.1467-6435.2011.00512.x

Frazier PA, Tix AP, Barron KE (2004) Testing moderator and mediator effects in counseling psychology research. J Couns Psychol 51:115-134. https://doi.org/10.1037/0022-0167.51.1.115

Hedström P, Swedberg R (1998) Social mechanisms: an analytical approach to social theory. Cambridge University Press, Cambridge

Hopkins DJ (2010) Politicized places: explaining where and when immigrants provoke local opposition. Am Polit Sci Rev 104:40-60. https://doi.org/10.1017/S00030554099903

Iacus SM, King G, Porro G (2009) CEM: software for coarsened exact matching. J Stat Softw 30. Copy at https://j.mp/2oSW6ty

Iacus SM, King G, Porro G (2012) Causal inference without balance checking: coarsened exact matching. Polit Anal 20(1):1-24. https://doi.org/10.1093/pan/mpr013

Imbens G, Kalyanaraman K (2012) Optimal bandwidth choice for the regression discontinuity estimator. Rev Econ Stud 79:933-959. https://doi.org/10.1093/restud/rdr043

Jungkunz S, Helbling M, Schwemmer C (2018) Xenophobia before and after the Paris 2015 attacks: evidence from a natural experiment. Ethnicities 19(2):271-291. https://doi.org/10.1177/1468796818 757264

Kalogeropoulos A, Hopmann DN (2019) Interpersonal discussions and immigration attitudes. Commun Eur J Commun Res 44(2):185-203. https://doi.org/10.1515/commun-2018-2007

Larsen E, Cutta D, Goodwin MJ (2019) Do terrorist attacks feed populist Eurosceptics? Evidence from two comparative quasi-experiments. Eur J Polit Res. https://doi.org/10.1111/1475-6765.12342

Legewie J (2013) Terrorist events and attitudes toward immigrants: a natural experiment. Am J Sociol 118(5):1199-1245. https://doi.org/10.1086/669605

Legewie J (2016) Racial profiling and use of force in police stops: how local events trigger periods of increased discrimination. Am J Sociol 122:379-424. https://doi.org/10.1086/687518

Mancosu M, Cappiali TM, Pereira MF (2018) The (non)-persistence of changes in attitudes toward immigrants after terrorist attacks: the case of the Manchester bombing. https://www.carloalberto.org/wpcontent/uploads/2018/11/no.549.pdf. Accessed 5 Feb 2019

Miller NE, Bugelski R (1948) Minor studies of aggression: II. The influence of frustrations imposed by the in-group on attitudes expressed toward out-groups. J Psychol 25:437-442

Muñoz J, Falcó-Gimeno A, Hernández E (2019) Unexpected event during surveys design: promise and pitfalls. Polit Anal. https://doi.org/10.1017/pan.2019.27

Nussio E, Bove V, Steele B (2019) The consequences of terrorism on migration attitudes across Europe. Polit Geogr. https://doi.org/10.1016/j.polgeo.2019.102047

Peffley M, Hutchison ML, Shamir M (2015) The impact of persistent terrorism on political tolerance: Israel, 1980 to 2011. Am Polit Sci Rev 109:817-832. https://doi.org/10.1017/S0003055415000441

Pettigrew TF (1998) Intergroup contact theory. Annu Rev Psychol 49:65-85. https://doi.org/10.1146/ annurev.psych.49.1.65

Rubaltelli E, Pittarello A (2018) Negative emotion and trait emotional intelligence in reaction to terrorist attacks. Person Individ Differ 123:247-252. https://doi.org/10.1016/j.paid.2017.11.036 
Rusu H, Gheorghita A (2014) Transnational solidarity and public support for the EU enlargement. Sociologia 46:261-282. https://doi.org/10.4232/1.11004

Schmidt-Catran AW, Czymara CS (2020) "Did you read about Berlin?" Terrorist attacks, online media reporting and support for refugees in Germany. Soziale Welt 71(2-3):305-337

Schüller S (2016) The effects of $9 / 11$ on attitudes toward immigration and the moderating role of education: effects of 9/11 on attitudes toward immigration. Kyklos 69:604-632. https://doi.org/10.1111/ kykl.12122

Smiley KT, Emerson MO, Markussen JW (2017) Immigration attitudes before and after tragedy in copenhagen: the importance of political affiliation and safety concerns. Sociol Forum 32:321-338. https:// doi.org/10.1111/socf.12332

Spilerman S, Stecklov G (2009) Societal responses to terrorist attacks. Ann Rev Sociol 35:167-189. https ://doi.org/10.1146/annurev-soc-070308-120001

van Dooremalen T (2017) The pros and cons of researching events ethnographically. Ethnography 18:415-424. https://doi.org/10.1177/1466138117709293

Publisher's Note Springer Nature remains neutral with regard to jurisdictional claims in published maps and institutional affiliations. 